RECENT ADVANCES

\title{
Bisphosphonate treatment of bone disease
}

\author{
N J Shaw, N J Bishop
}

Arch Dis Child 2005;90:494-499. doi: 10.1136/adc.2003.036590

In 1997 a review article on bisphosphonates in this journal identified 24 published articles relating to children at that time.' Since then there has been a considerable increase in their use in clinical paediatric practice and research with there being nearly a further one hundred articles published at the time of writing.

See end of article for authors' affiliations

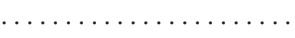

Correspondence to:

Dr N J Shaw, Dept of

Endocrinology,

Birmingham Children's

Hospital, Steelhouse Lane,

Birmingham B4 6NH, UK;

nick.shaw@bch.nhs.uk

Accepted

15 November 2004
$\mathrm{T}$ he purpose of this review is to identify what new information has been gained over the past seven years and to provide our opinions for the future use of such drugs in children and what further research needs to be undertaken.

\section{MECHANISM OF ACTION AND RELATIVE POTENCY}

Bisphosphonates are chemical analogues of pyrophosphate. The presence of a carbon rather than oxygen atom at the centre of the molecule prevents its breakdown. The two phosphonate groups are attached directly to the carbon atom from which also extend the R1 and R2 side chains (fig 1). The Rl side chain is usually a hydroxyl group and is often referred to as the "bone hook" in association with the phosphonic groups. It is the R2 side chain that confers the differential potency of the different molecules. The older bisphosphonates, etidronate and clodronate, form cytotoxic acyclic ATP analogues which accumulate in osteoclasts (following endocytosis from bone surfaces), leading to apoptosis (programmed cell death). ${ }^{2}$ The more recent nitrogen containing bisphosphonates cause inhibition of farnesyl diphosphate synthase. $^{3}$ This inhibition leads to failure of prenylation (transfer of fatty acid chains) of a variety of intracellular proteins, particularly small GTP binding proteins such as Ras, Rab, Rho, and Rac. Failure of prenylation leads to the inability of these small proteins to translocate into cell membranes. The resulting interference with cellular processes leads to earlier apoptosis of several cell types including osteoclasts. ${ }^{4}$ At the cellular level, the loss of osteoclast function leads to a reduction in bone resorption and, hence, a cascade of events (fig 2).

The commonly used nitrogen containing bisphosphonates comprise pamidronate, olpadronate, ibandronate, alendronate, risedronate, and zoledronate. Their relative potency which has been assessed in in-vitro assays for osteoclast inhibition and the effect on pit formation of osteoclasts seeded onto dentine slices, are shown in table 1 , taking etidronate as having a potency of 1 .
Debate continues about relative potency in vivo of the commonly used nitrogen containing bisphosphonates in adult osteoporosis trials, although similar levels of inhibition of bone function are achieved with alendronate and risedronate. ${ }^{5}$ Bone mass is maintained in adults after stopping bisphosphonate therapy. This introduces the concept of "residence time". Zoledronate clearly has the longest residence time of any of the bisphosphonates and a single dose is sufficient to inhibit bone resorption for up to 12 months in adult osteoporosis studies. ${ }^{6}$

A pharmacokinetic study of alendronate has been undertaken and reported in the literature of the FDA. The overall absorption of alendronate when given by mouth is similar in children to that in adults at around $0.5 \%$ of the administered dose.

\section{CLINICAL APPLICATIONS}

These can be broadly divided into three categories as previously delineated: ${ }^{7}$ diseases associated with pathological effects on the skeletonthat is, osteopathy; those associated with hypercalcaemia; and conditions associated with soft tissue calcification-that is, calcinosis.

\section{Osteopathy}

Intravenous bisphosphonates

There has been considerable interest in the use of these drugs in children with osteogenesis imperfecta (OI) who are the most studied group of children receiving bisphosphonates. Although there had been previous case reports of their use in this condition, the first detailed report of a large number of children was published in $1998 .{ }^{8}$ Thirty children aged 3-16 years with severe forms of the condition were treated with intravenous pamidronate $1 \mathrm{mg} / \mathrm{kg}$ /day for three consecutive days every four to six months for $1.3-5.0$ years. The mean annual increment in spinal bone density (BMD) was $42 \%$, with a reduction in fracture incidence of 1.7 per year, and more than $50 \%$ of the study population showed improved mobility. A similar large study ${ }^{9}$ has reproduced these results using monthly infusions of pamidronate in dosages of 10$40 \mathrm{mg} / \mathrm{m}^{2}$. The increase in bone density has been shown to be due to a combination of increased bone size and volumetric bone density which correlates with the remodelling of collapsed vertebrae seen on $x$ ray in treated patients. ${ }^{10}$ The effect of treatment on bone turnover in this group has shown that urinary NTx/creatinine ratios, a marker of bone resorption, fell from a mean value of $132 \%$ at baseline to $49 \%$ after four years of treatment in comparison to values expected in age and sex matched controls. ${ }^{11} \mathrm{~A}$ reduction in bone pain and improvements in 

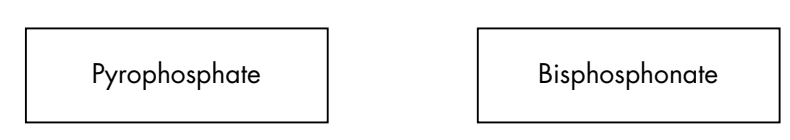

$=\left.\right|_{0} ^{O}-O-\left.\right|_{O} ^{P}=0$

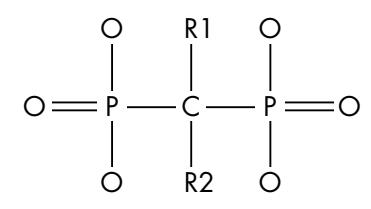

Figure 1 Structure of pyrophosphate and bisphosphonate.

confidence and general wellbeing have been subjectively reported by many children, and an objective improvement in grip strength has been documented after four months of the first treatment, which is maintained for at least two years. ${ }^{12}$ Although no relation between OI type and treatment effect has been shown, there is an inverse relation with baseline bone mineral content (BMC) with the most severely affected individuals having the largest increments in BMC. ${ }^{13}$

The impact on bone histology has been reported in a group of 45 patients before and after 2.4 years of treatment. ${ }^{14}$ Cortical width was shown to increase by $88 \%$ and cancellous bone volume by $46 \%$ due to an increase in trabecular number rather than thickness. No evidence of a mineralisation defect was seen in this study. A study in infants under the age of 3 years with severe $\mathrm{OI}^{15}$ used a more frequent dosage regime of $0.5 \mathrm{mg} / \mathrm{kg} /$ day on three consecutive days every six weeks due to the anticipated higher bone turnover. In comparison to historical controls they showed a dramatic increase in BMD of $86-227 \%$, a reduction in fracture incidence, improved handling by carers, and remarkable remodelling of previously deformed bones.

Although studies in children with OI have been criticised because of the lack of randomised controlled studies, the marked changes seen in various parameters are unlikely to be a chance event. Currently bisphosphonate treatment would be regarded as an important component of the multidisciplinary approach to children with severe OI.

Several other patient groups have shown beneficial effects from the use of bisphosphonates on bone density and fracture frequency. Most of these studies have used intravenous pamidronate (dose range $2-15 \mathrm{mg} / \mathrm{kg} / \mathrm{y}$ ) given every three to six months and include glucocorticoid induced osteoporosis, ${ }^{16}$ osteoporosis-pseudoglioma syndrome, ${ }^{17}$ Menkes disease, ${ }^{18}$ and cerebral palsy. ${ }^{19}$ Although most studies have utilised a schedule of three consecutive daily infusions of $1 \mathrm{mg} / \mathrm{kg}$ of pamidronate, one study ${ }^{20}$ which examined the use of single day infusions of the same dose showed median increases of $23.5 \%$ in lumbar spine bone density after six months and a reduction in fracture rate from an average of 1.9 per year pretreatment to 0.2 in the follow up period of 622 months.

\section{Oral bisphosphonates}

Studies examining the efficacy of oral bisphosphonates in children are limited, in contrast to the experience in adult practice where they are the primary means of treatment for osteoporosis. One of the early studies used oral pamidronate or olpadronate in 12 children (four of whom had osteogenesis imperfecta and six with idiopathic osteoporosis) for 2-8 years. ${ }^{21}$ The change in the mean spinal bone density standard deviation score (Z-score) was from -3.8 to -1.9 over five years, with a reduction in the number of fractures in those with OI. A recent study from the Netherlands examined the use of olpadronate in children with OI given in a daily dose of $10 \mathrm{mg} / \mathrm{m}^{2}$ by mouth, in a randomised placebo controlled trial
Table 1 Relative potency of bisphosphonates to inhibit bone resorption

\begin{tabular}{ll}
\hline Bisphosphonate & Relative potency \\
\hline Etidronate & 1 \\
Clodronate & 10 \\
Pamidronate & 100 \\
Olpadronate & $200-500$ \\
lbandronate & $500-1000$ \\
Alendronate & $1000-2000$ \\
Risedronate & 2000 \\
Zoledronate & 10000 \\
\hline
\end{tabular}

for a period of two years. ${ }^{22}$ There was a larger rise in spinal bone density in the active treatment group (Z-score improved from -4.98 to -3.31 ) than the placebo group (Z-score improved from -4.84 to -4.70 ). There were fewer fractures in the olpadronate treated group, with a $31 \%$ reduction in relative fracture risk. Despite these changes there were no detectable differences in functional outcome, grip strength, lumbar vertebral height, or urinary markers of bone resorption. The lack of beneficial effect on functional outcome is in contrast to the previously reported uncontrolled studies using intravenous pamidronate. No child who received active treatment reported gastrointestinal upset or had evidence of renal or hepatic dysfunction.

One study of 38 children $^{23}$ with connective tissue disease, 30 of whom were receiving continuous glucocorticoid therapy for at least six months, evaluated the use of alendronate over a period of one year. Subjects weighing less than $20 \mathrm{~kg}$ received a dose of $5 \mathrm{mg}$ daily and those greater than $20 \mathrm{~kg}$ received $10 \mathrm{mg}$ daily. Lumbar spine BMD increased by a mean of $14.9 \%$, in comparison to an increment of $2.6 \%$ in an untreated control group containing patients with less severe disease. There were insufficient duration and numbers to comment on effects on fracture incidence. Apart from some reports of gastrointestinal irritation the drug was well tolerated. There are currently few studies of oral bisphosphonate usage in children containing a significant number of children with the same condition to enable decisions to be made regarding their efficacy, and there are no studies comparing oral to intravenous bisphosphonates in the same condition.

\section{Hypercalcaemia}

Bisphosphonates have been used in children with hypercalcaemia due to a variety of causes including immobilisation, leukaemia, hyperparathyroidism, and subcutaneous fat necrosis. A retrospective review ${ }^{24}$ of the use of intravenous pamidronate in five children with hypercalcaemia associated with malignancy showed successful resolution within 48 hours with single infusions of $1-2 \mathrm{mg} / \mathrm{kg}$. One patient developed symptomatic hypocalcaemia and two developed transient hypophosphataemia. Intravenous pamidronate in doses of $35-60 \mathrm{mg} / \mathrm{m}^{2}$ also proved successful in children with advanced liver disease and hypercalcaemia prior to liver transplantation..$^{25}$ Another report documents responses to intravenous pamidronate in doses ranging from 0.5 to $1.0 \mathrm{mg} / \mathrm{kg}$ in three children with hypercalcaemia of differing aetiology. ${ }^{26}$ Oral etidronate in a dose of $3.7 \mathrm{mg} / \mathrm{kg} /$ day proved effective in normalising plasma calcium within two weeks in a child with immobilisation induced hypercalcaemia secondary to Guillain-Barré syndrome. ${ }^{27}$ Etidronate was also used in a dose of $5 \mathrm{mg} / \mathrm{kg}$ twice daily in a 1 month old infant with hypercalcaemia secondary to subcutaneous fat necrosis ${ }^{28}$ who had failed to respond to intravenous saline, frusemide, and prednisone, with the plasma calcium normalising within 24 hours. We are also aware of the use of intravenous 


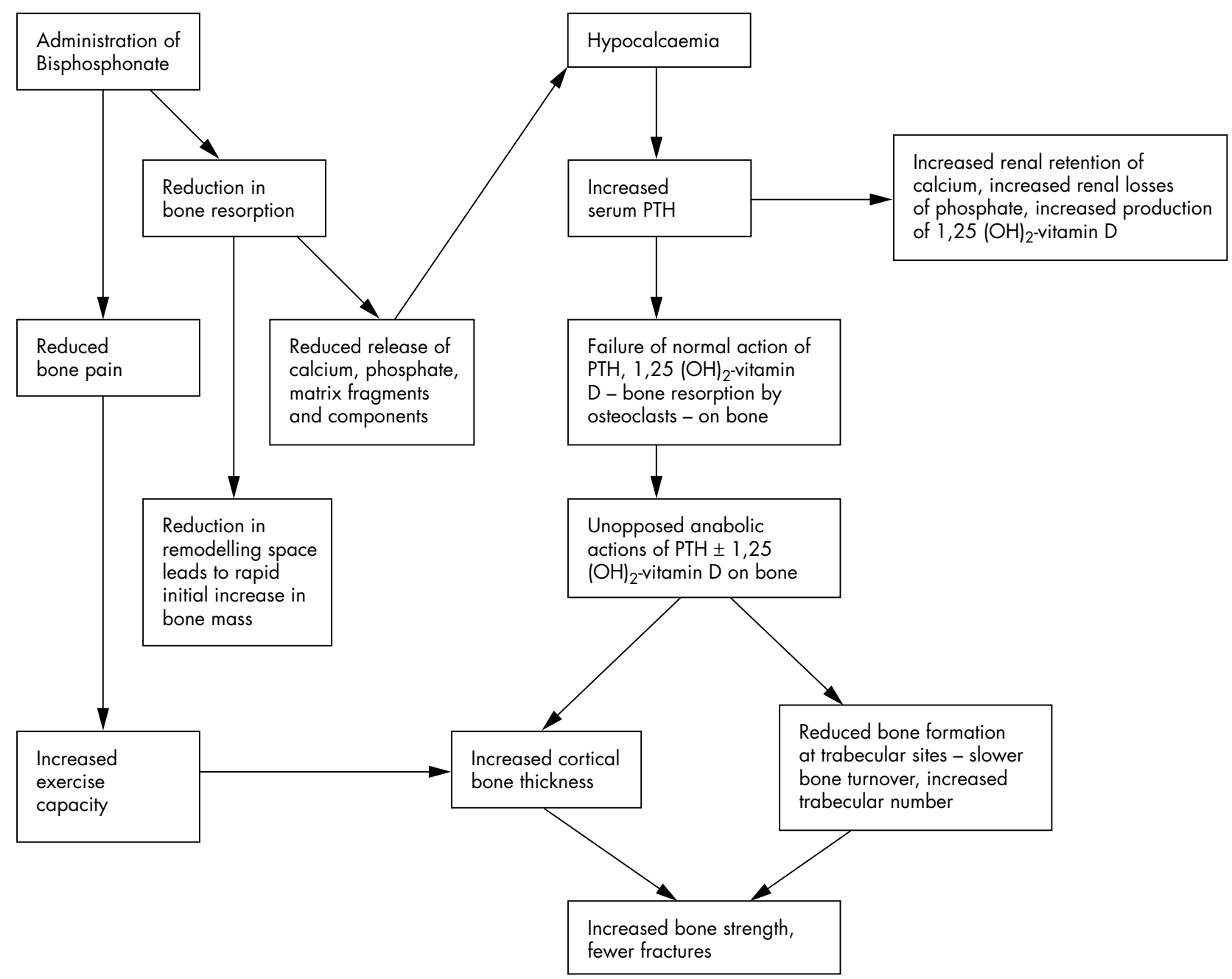

Figure 2 Cascade of events triggered by administration of a bisphosphonate.

pamidronate in the treatment of hypercalcaemia due to neonatal severe hyperparathyroidism ${ }^{29}$ and immobilisation hypercalcaemia following spinal cord injury. ${ }^{30}$

\section{Calcinosis}

In contrast to their use in osteopathy and hypercalcaemia there have been few further reports of the use of bisphosphonates in conditions associated with calcinosis in paediatric practice such as dermatomyositis, fibrodysplasia ossificans progressiva, and scleroderma. One report of a 6 year old child with extensive subcutaneous calcification secondary to dermatomyositis documents the use of oral alendronate in a dose of $10 \mathrm{mg}$ daily for one year. ${ }^{31}$ During this time the bouts of fever and cellulitis related to the calcinosis ceased and the range of joint movements improved within six months, with radiological resolution of calcified deposits in the axilla and extrusion of several calcified deposits through the skin.

\section{Miscellaneous conditions}

Fibrous dysplasia is a condition in which bone marrow cells are affected by somatic activating mutations of the gene encoding the $\alpha$ subunit of the stimulatory G $\alpha$ protein Gs $\alpha$. In this condition dysplastic lesions within the skeleton can cause bone pain, cranial nerve compression, bone deformity, and fractures. It may occur in isolation or more commonly as part of the McCune-Albright syndrome. Intravenous pamidronate has been used in several small studies with reports of improvement in bone pain and a reduction in markers of bone turnover. Although a study in adults ${ }^{32}$ reported refilling of the dysplastic bone lesions in approximately $50 \%$ of patients, a detailed $x$ ray and histological study in 18 children and adolescents treated with pamidronate for at least one year did not confirm this effect..$^{33}$ Iliac crest bone biopsies containing dysplastic lesions showed no effect of treatment on parameters of bone resorption and a progression in the bone deformity necessitated orthopaedic surgery in seven patients. Thus it would appear that in this particular patient group the only indication for such treatment would be uncontrollable bone pain.

Idiopathic hyperphosphatasia is a rare autosomal recessive bone disorder characterised by excessive bone resorption and bone formation which may present in infancy or later childhood. Most cases are due to inactivating mutations in the gene coding for osteoprotegerin. Progressive bone deformity and fractures often lead to loss of ambulation by the teenage years. An 11 year old girl with this condition, ${ }^{34}$ who had failed to respond to conventional monthly doses of pamidronate, was then treated with intravenous ibandronate; $5 \mathrm{mg}$ infusions were given every month until suppression of alkaline phosphatase levels was achieved. She received $45 \mathrm{mg}$ over three years, during which biochemical markers of bone turnover were suppressed into the normal range; she had no further fractures and she remained mobile 
and active at an age when two older affected siblings had become wheelchair bound. There were no adverse effects on bone mineralisation in a bone biopsy taken after 18 months of treatment.

There are also preliminary reports of the use of pamidronate in chronic recurrent multifocal osteitis. ${ }^{35}$

\section{ADVERSE EFFECTS}

The most commonly used protocol of $1 \mathrm{mg} / \mathrm{kg} /$ day on three successive days of pamidronate given intravenously results in an acute phase reaction characterised by high temperature, musculoskeletal aches and pains, and, occasionally, vomiting which is seen in up to $85 \%$ of patients. It is uncommon for the reaction to recur on subsequent cycles of treatment at this dose level. However, anecdotal information (personal communication, David Sillence) indicates that lower doses of pamidronate may be associated with a recurrence of the acute phase reaction on subsequent administration. Four infants with severe OI and preexisting respiratory compromise developed respiratory distress during their first treatment with pamidronate. Two of them required intensive care admission. ${ }^{36}$ Acute reactions in relation to the administration of oral therapy have been seen with both alendronate and risedronate (personal communication, Francis Glorieux), with a lower grade but similar reaction to that seen in pamidronate, usually extending over a period of several days. Gastrointestinal upset has been reported with all orally administered bisphosphonates; risedronate is claimed to be less irritative than alendronate.

There have been several recent reports of severe symptomatic hypocalcaemia occurring after the administration of intravenous pamidronate or zoledronate. ${ }^{37} 38$ These occurred in individuals who either had undiagnosed vitamin D deficiency or hypoparathyroidism as a consequence of hypomagnesaemia or surgery. The importance of screening individuals appropriately prior to the use of a bisphosphonate is apparent. There have also been several reports of osteonecrosis of the jaw occurring in adult patients who have received intravenous pamidronate or zoledronate. ${ }^{39}$ These have usually occurred in patients with malignancy and other risk factors for osteonecrosis; no causal relation has been established.

Potentially more serious problems have arisen from the over-zealous administration of pamidronate for non-specific bone pain, as reported by Whyte and colleagues. ${ }^{40}$ In a child given the typical cycle of pamidronate at monthly intervals, they reported severe under-tubulation at the growing ends of long bones with an appearance not dissimilar to that seen in osteopetrosis which, presumably, had resulted from the failure to re-model the metaphyseal diaphyseal junction. A further report of slower than expected fracture healing, and healing after osteotomies, was given at the American Society of Bone and Mineral Research in 2003. ${ }^{41}$ The slower healing was noted particularly in children with OI who had received bisphosphonates for three or more years and where osteotomies had been undertaken using a vibrating saw, possibly cauterising the ends of the bones prior to intramedullary rodding. Recent work has identified that the sclerotic metaphyseal lines seen at the ends of the long bones in children treated with pamidronate are due to retention of calcified cartilage which with time are replaced with bone. ${ }^{42}$ It remains unclear whether there are likely to be longer term consequences of chronic bisphosphonate administration. Particularly with the drugs that have longer residence time in bone, consideration should be given to the potential for retention in bone, and release at a later date, perhaps during pregnancy in young women.

\section{UNANSWERED QUESTIONS}

Although there has been a considerable addition to the published literature on the use of bisphosphonates in children since 1997, there remain a number of unanswered questions which would benefit from future research. These include:

- Criteria used to initiate treatment. In a scenario where a child is having recurrent low trauma fractures in conjunction with an abnormal bone density, the potential benefit from bisphosphonate treatment would outweigh any potential risk. However, this may not be the case for a child with a low bone density in the absence of fractures and it would appear inappropriate to administer bisphosphonates in this situation unless there were good evidence that the child was at high risk of fractures. Therefore future studies need to include outcome measures other than change in bone density, such as reduction in fracture frequency, which should ideally be performed as randomised controlled studies. The use of bisphosphonates in children with mild forms of OI who have infrequent fractures should be examined to ensure that the potential benefits on bone density and fracture frequency outweigh any potential risks.

- Duration of treatment. There is currently little information to guide clinicians as to duration of treatment and what criteria should be used to indicate stopping treatment. Such criteria are likely to vary depending on the condition being treated; for example, a child with steroid induced osteoporotic fractures may only need treatment for one year, while a child with OI may require more prolonged treatment. The criteria used are likely to include bone density, fracture frequency, mobility, and biochemical markers of bone turnover. However, the urinary NTX/ creatinine ratio was not associated with histomorphometric measures of cancellous bone metabolism in children with osteogenesis imperfecta during treatment, so it is unclear as to the role of biochemical markers in monitoring therapy. ${ }^{14}$

- Duration of treatment effect. It is currently unclear how long the effect of bisphosphonate treatment will last once discontinued. Again this is likely to be related to the condition being treated; for example, the impact on a child with juvenile arthritis will be related to the disease activity and the dosage of glucocorticoids.

- Dose and frequency of administration. In the treatment of children with OI with intravenous pamidronate, most clinicians utilise a regime developed in Montreal of three infusions on consecutive days, with smaller but more frequent doses being used in younger children. ${ }^{43}$ However, other dosage regimes varying from monthly to six monthly regimes have been used in OI and other conditions. Therefore further research to identify the lowest effective dose and treatment frequency is indicated.

- Role of other bisphosphonates. There are now a variety of different bisphosphonates that are available for clinical use which vary significantly in their potency. For example, ibadronate and zoledronate, which are administered intravenously, have potencies that are 10 and 100 times that of pamidronate. Zoledronate is currently being investigated in an international study in children with OI; if shown to be effective and free of significant adverse effects, it will have the advantage that it can be administered over 30 minutes as a single infusion every three months, thus reducing the need for hospital admission. There have been some preliminary studies examining the efficacy of oral bisphosphonates and further studies are indicated, including a comparison of an oral to an intravenous bisphosphonate. 
- Use as prophylaxis. The majority of current usage in children is for conditions with significant clinical effects, for example, fractures in OI and bone pain in fibrous dysplasia. We are aware of them being administered prophylactically in conditions where a child has been identified as having a low bone density in the absence of fractures, and it has been felt important by the clinician responsible to offer treatment. However, in many of these conditions there is currently a lack of good evidence that the low bone density leads to an increased fracture frequency in the short or long term, and such studies are necessary to justify the use of prophylactic treatment. One condition where there is a high prevalence of abnormal bone density and fractures is juvenile idiopathic arthritis. A multicentre study in the UK is due to commence, which will examine the prophylactic use of a bisphosphonate. In many conditions where abnormal bone density has been identified, there is a need to understand the aetiology, as such knowledge may lead to alternative methods of prevention and treatment; for example, the role of hypogonadism in thalassaemia and the importance of appropriate sex steroid replacement in this group. ${ }^{44}$

\section{WHO SHOULD BE TREATING AND MONITORING PATIENTS?}

The availability of bisphosphonates is undoubtedly a significant advance in the therapeutic armamentarium for bone disease in children. However, the case report of bisphosphonate induced osteopetrosis ${ }^{40}$ illustrates the potential risks of misinterpretation of clinical information and the inappropriate use of a bisphosphonate. Such a case is unlikely to be isolated. The availability of bone densitometry for children leads to the identification of many children with chronic disease who have abnormal results, leading to a temptation for the clinician to administer treatment with a bisphosphonate. The potential pitfalls in the use of bone densitometry in children are not widely appreciated, ${ }^{45}$ and incorrect interpretation may lead to misdiagnosis of abnormal bone density. The management of osteoporosis and related bone disorders in children is an evolving discipline with few clear guidelines to date. In view of these issues we would support the view that bisphosphonate therapy should be used only in the context of a well run clinical programme with specialist knowledge in the management of bone disease in children. ${ }^{46}$

\section{Authors' affiliations}

N J Shaw, Department of Endocrinology, Birmingham Children's Hospital, UK

N J Bishop, Academic Unit of Child Health, Sheffield Children's Hospital, University of Sheffield, UK

Competing interests: NJS and NJB have received funding from Novartis and the Arthritism \& Rheumatism Council for studies of bisphosphonates in osteogenesis imperfecta. NJB has acted as an independent consultant for Proctor \& Gamble.

\section{REFERENCES}

1 Allgrove J. Biphosphonates. Arch Dis Child 1997;76:73-5.

2 Rogers MJ, Ji X, Russell RG, et al. Incorporation of bisphosphonates into adenine nucleotides by amoebae of the cellular slime mould Dictyostelium discoideum. Biochem J 1994;303:303-11.

3 Luckman SP, Hughes DE, Coxon F, et al. Nitrogen-containing bisphosphonates inhibit the mevalonate pathway and prevent posttranslational prenylation of GTP-binding proteins, including Ras. J Bone Miner Res 1998;13:581-9.

4 Benford HL, McGowan NW, Helfrich MH, et al. Visualization of bisphosphonate-induced caspase-3 activity in apoptotic osteoclasts in vitro. Bone $2001 ; 28: 465-73$.

5 Hosking D, Adami S, Felsenberg D, et al. Comparison of change in bone resorption and bone mineral density with once-weekly alendronate and daily risedronate: a randomised, placebo-controlled study. Curr Med Res Opin 2003; 19:383-94.

6 Reid IR, Brown JP, Burckhardt P, et al. Intravenous zoledronic acid in postmenopausal women with low bone density. N Engl J Med 2002;346:653-61.

7 Shoemaker LR. Expanding role of bisphosphonate therapy in children. J Pediatr 1999;134:264-7

8 Glorieux FH, Bishop NJ, Plotkin $\mathrm{H}$, et al. Cyclic administration of pamidronate in children with severe osteogenesis imperfecta. N Engl J Med 1998;339:947-52

9 Astrom E, Soderhall S. Beneficial effect of long term intravenous bisphosphonate treatment of osteogenesis imperfecta. Arch Dis Child 2002;86:356-64.

10 Rauch F, Plotkin H, Zeitlin L, et al. Bone mass, size, and density in children and adolescents with osteogenesis imperfecta: effect of intravenous pamidronate therapy. J Bone Miner Res 2003;18:610-14.

11 Rauch F, Plotkin H, Travers R, et al. Osteogenesis imperfecta types I, III, and IV: effect of pamidronate therapy on bone and mineral metabolism. J Clin Endocrinol Metab 2003;88:986-92.

12 Montpetit K, Plotkin H, Rauch F, et al. Rapid increase in grip force after start of pamidronate therapy in children and adolescents with severe osteogenesis imperfecta. Pediatrics 2003;111:e601-3.

13 Zacharin M, Bateman J. Pamidronate treatment of osteogenesis imperfecta: lack of correlation between clinical severity, age at onset of treatment, predicted collagen mutation and treatment response. J Pediatr Endocrinol Metab 2002;15:163-74.

14 Rauch F, Travers R, Plotkin $\mathrm{H}$, et al. The effects of intravenous pamidronate on the bone tissue of children and adolescents with osteogenesis imperfecta. J Clin lnvest 2002;110:1293-9.

15 Plotkin H, Rauch F, Bishop NJ, et al. Pamidronate treatment of severe osteogenesis imperfecta in children under 3 years of age. J Clin Endocrinol Metab 2000;85: 1846-50.

16 Noguera A, Ros JB, Pavia C, et al. Bisphosphonates, a new treatment for glucocorticoid-induced osteoporosis. J Pediatr Endocrinol Metab 2003; 16:529-36

17 Zacharin M, Cundy T. Osteoporosis pseudoglioma syndrome: treatment of spinal osteoporosis with intravenous bisphosphonates. J Pediatr 2000;137:410-15.

18 Kanumakala S, Boneh A, Zacharin M. Pamidronate treatment improves bone mineral density in children with Menkes disease. J Inherit Metab Dis 2002;25:391-8.

19 Henderson RC, Lark RK, Kecskemethy HH, et al. Bisphosphonates to treat osteopenia in children with quadriplegic cerebral palsy: a randomised placebo-controlled clinical trial. J Pediatr 2002;141:644-51.

20 Steelman J, Zeitler P. Treatment of symptomatic pediatric osteoporosis with cyclic single-day intravenous pamidronate infusions. J Pediatr 2003;142:417-23.

21 Brumsen C, Hamdy NAT, Papapoulos SE. Long term effects of bisphosphonates on the growing skeleton. Medicine 1997;76:266-83.

22 Sakkers R, Kok D, Engelbert R, et al. Skeletal effects and functional outcome with olpadronate in children with osteogenesis imperfecta: a 2-year randomised placebo-controlled study. Lancet 2004;363:1427-31.

23 Bianchi ML, Cimaz R, Bardare M, et al. Efficacy and safety of alendronate for the treatment of osteoporosis in diffuse connective tissue diseases in children. Arthritis Rheum 2000;43:1960-6.

24 Young G, Shende A. Use of pamidronate in the management of acute cancerrelated hypercalcaemia in children. Med Pediatr Oncol 1998;30:117-21.

25 Attard TM, Dhawan A, Kaufman SS, et al. Use of disodium pamidronate in children with hypercalcaemia awaiting liver transplantation. Pediatric Transplantation 1998;2:157-9.

26 Lteif AN, Zimmerman D. Bisphosphonates for treatment of childhood hypercalcaemia. Pediatrics 1998;102:990-2.

27 Go T. Low-dose etidronate therapy for immobilisation hypercalcaemia associated with Guillain-Barre syndrome. Acta Paediatr 2001;90:1202-4.

28 Rice AM, Rivkees SA. Etidronate therapy for hypercalcaemia in subcutaneous fat necrosis of the newborn. J Pediatr 1999;134:349-51.

29 Waller SC, Van't Hoff W. Pamidronate therapy in hyperparathyroid bone disease with severe hypercalcaemia. Arch Dis Child 2003;88(suppl 1):A74.

30 Kedlaya D, Brandstater ME, Lee JK. Immobilization hypercalcaemia in incomplete paraplegia: successful treatment with pamidronate. Arch Phys Med Rehabil 1998;79:222-5.

31 Mukamel M, Horev G, Mimouni M. New insight into calcinosis of juvenile dermatomyositis: a study of composition and treatment. J Pediatr $2001 ; 138: 763-6$

32 Chapurlat RD, Delmas PD, Liens D, et al. Long term effects of intravenous pamidronate in fibrous dysplasia of bone. J Bone Miner Res 1997; 12:1746-52.

33 Plotkin H, Rauch F, Zeitlin L, et al. Effect of pamidronate treatment in children with polyostotic fibrous dysplasia of bone. J Clin Endocrinol Metab 2003;88:4569-75.

34 Cundy T, Wheadon L, King A. Treatment of idiopathic hyperphosphatasia with intensive bisphosphonate therapy. J Bone Miner Res 2004;19:703-11.

35 Cleary AG, Davidson JE, Sills JA. Pamidronate treatment in chronic recurrent multifocal osteitis and SAPHO syndrome. Arch Dis Child 2003;88(suppl 1):A38.

36 Munns CF, Rauch F, Mier RJ, et al. Respiratory distress with pamidronate treatment in infants with severe osteogenesis imperfecta. Bone 2004;35:231-4.

37 Peter R, Mishra V, Fraser WD. Severe hypocalcaemia after being given intravenous bisphosphonate. BMJ 2004;328:335-6. 
38 Rosen CJ. Severe hypocalcaemia after intravenous bisphosphonate therapy in occult vitamin D deficiency. N Engl J Med 2003;348:1503-4.

39 Marx RE. Pamidronate (Aredia) and Zoledronate (Zometa) induced avascular necrosis of the jaws: a growing epidemic. J Oral Maxillofac Surg 2003:61:1238-9.

40 Whyte MP, Wenkert D, Clements KL, et al. Bisphosphonate-induced osteopetrosis. N Engl J Med 2003;349:457-63.

41 Munns CFJ, Rauch F, Zeitlin L, et al. Delayed fracture and osteotomy healing in pediatric osteogenesis imperfecta patients receiving pamidronate. J Bone Miner Res 2003; 18(suppl 2):S33.
42 Rauch F, Travers R, Munns C, et al. Sclerotic metaphyseal lines in a child treated with pamidronate: histomorphometric analysis. J Bone Miner Res 2004; 19:1191-3.

43 Rauch F, Glorieux FH. Osteogenesis imperfecta. Lancet 2004:363:1377-85.

44 Bielinski BK, Darbyshire PJ, Mathers L, et al. Impact of disordered puberty on bone density in $\beta$ thalassaemia major. Br J Haematol 2003;120:353-8.

45 Fewtrell MS. Bone densitometry in children assessed by dual $x$ ray absorptiometry: uses and piffalls. Arch Dis Child 2003;88:795-8.

46 Batch JA, Couper JJ, Rodda C, et al. Use of bisphosphonate therapy for osteoporosis in childhood and adolescence. J Paediatr Child Health 2003;39:88-92.

\section{ARCHIVIST}

\section{Preparing for transfer to a clinic for adults}

Co young people with chronic disease the process of transfer from paediatric to adult

- care may be stressful, and prolonged and careful preparation may be needed. Paediatric rheumatologists in Birmingham (KM Bailey and colleagues. Annals of Rheumatic Diseases 2004;63:1544-8) refer to the event of transfer and the process of transition. During transition many factors need to be considered that affect the medical, psychosocial, and educational and career needs of the young person. In too many cases transfer is a sudden event with little or no apparent prior consideration.

The Birmingham team take as an example the case of a young man with juvenile idiopathic arthritis (JIA) who was recently transferred to adult care at the age of 19 years. He had developed systemic JIA at the age of 2 years and had suffered many of the complications of severe disease including small stature, delayed puberty, osteoporosis, and joint destruction. He had had many drug treatments (steroids, nonsteroidal antiinflammatory drugs, penicillamine, methotrexate, ciclosporin, intravenous immunoglobulin, rifampicin, isoniazid, and etanercept) and many operations (synovectomy, supracondylar osteotomies, replacement of one hip at age 12, the other hip at age 19, knees at ages 15 and 17 , and cervical fusion and odontoidectomy). He has an electric wheelchair and is about to learn to drive a modified car. In spite of all his troubles he is now at university.

This young man has been prepared gradually for transfer to adult care since the age of 11 when the suggestion that he should be seen alone in clinic, or choose who should attend, was introduced. The eventual transfer to adult care was discussed from the age of 15. When the transfer occurred he was seen initially in a young adult clinic with his paediatric rheumatologist present. An individualised transition plan was worked out that referred to transitions in health, home activities, and educational and career plans. Control of disease activity needs to be as good as possible at the time of transfer and parental anxiety needs to be anticipated. Adolescents with chronic disease often know surprisingly little about their disease (for instance, two thirds of adolescents with JIA in a recent study were unaware of what the letters JIA stood for).

Disease education should be reviewed before transfer. Young people with chronic disease need careful preparation for transfer to adult care and professionals who care for young people, both paediatricians and specialists in the medicine of adults, should be trained in adolescent health. 